\title{
Karakterisasi Reservoar Menggunakan Aplikasi Seismik Atribut dan Inversi Seismik Impedansi Akustik, Studi Kasus Lapangan Teapot Dome, Wyoming
}

\author{
Nur Muhammad Zain, Wien Lestari, dan Firman Syaifuddin \\ Departemen Teknik Geofisika, Fakultas Teknik Sipil dan Perencanaan, Institut Teknologi Sepuluh Nopember (ITS) \\ e-mail:wien@geofisika.its.ac.id
}

\begin{abstract}
Abstrak-Lapangan Teapot Dome, Wyoming terletak di Powder Basin yang merupakan cekugan prospek hidrokarbon. Data yang digunakan pada penelitian ini yaitu data seismik 3D Post Stack dan 7 data sumur. Zona target terletak pada F1WC dan Redpeak. Zona target memiliki litologi berupa sand dan shaly sand. Dilakukan karakterisasi reservoar pada kedua zona target guna mengevaluasi zona. Kedua data diintegrasi menggunakan metode inversi berbasis model dan metode seismik multiatribut. Metode inversi berbasis model dilakukan guna memprediksi impedansi akustik. Metode seismik multiatribut menggunakan lebih dari satu atribut untuk memprediksi parameter sumur. Parameter yang dicari pada penelitian ini yaitu porositas sehingga didapat persebaran porositas dalam volume seismik. Digunakan pula metode Probabilistic Neural Network guna meningkatkan hasil korelasi antara data seismik dengan data sumur saat memprediksi porositas. Berdasarkan hasil yang didapatkan diketahui bahwa karakter reservoar zona F1WC yaitu impedansi akustik pada rentang $27000-34000(\mathrm{ft} / \mathrm{s})(\mathrm{gr} / \mathrm{cc})$ dan porositas $8-11 \%$. Sedangkan untuk zona RDPK mempunyai rentang nilai impedansi akustik 34000-49000 (ft/s)(gr/cc) dan porositas 5-10\%. Berdasarkan justifikasi karakter log, inversi, dan multiatribut diketahui bahwa kedua zona target merupakan zona prospek hidrokarbon.
\end{abstract}

Kata Kunci-Karakterisasi Reservoar, Model Based Inversion, Probabilistic Neural Network.

\section{PENDAHULUAN}

K ARAKTERISASI reservoar merupakan suatu proses guna menjabarkan secara kualitatif maupun kuantitatif karakter reservoar menggunakan seluruh data yang ada. Sedangkan karakterisasi reservoar seismik merupakan suatu proses pendeskripsian secara kualitatif maupun kuantitatif suatu reservoar dengan menggunakan data seismik sebagai data utama. Data pendukung yang digunakan yaitu data wireline log. Seismik inversi merupakan salah satu metode yang digunakan oleh ahli geofisika untuk mengarakterisasi reservoar. Seismik inveri adalah suatu teknik pembuatan model geologi bawah permukaan dengan data seismik sebagai input dan data geologi sebagai kontrol [1]. Data log sumur mempunyai keakuratan secara vertikal yang lebih baik, dimana akan digabungkan dengan nilai impedansi akustik dari hasil inversi data seismik yang baik pada arah lateral. Maka akan didapatkan parameter-parameter fisis yang akurat guna menganalisis reservoar dengan nilai kesalahan yang minim. Teknik pengembangan reservoar hidrokarbon ini menggunakan data seismik dalam analisis litologi maupun kandungan fluida reservoar.

Data sumur yang digunakan berjumlah sumur yang diambil berdasarkan kedalaman yang mencapai zona target. Zona target pada penelitian ini yaitu F1WC dan RDPK yang dipilih karena belum terdapat penelitian di kedua zona tersebut sekaligus. Ketujuh sumur yang digunakan mempunyai kelengkapan data yang hampir sama yaitu minimal mempunyai log sonik, gamma ray, densitas, neutron, dan resistivitas. Data seismik juga sudah tersedia pada lapangan ini dalam bentuk 3D PSTM.

Multiatribut pada dasarnya merupakan suatu proses ekstraksi beberapa atribut dari data seismik yang mempunyai korelasi yang baik terhadap data log yang kemudian digunakan untuk memprediksi parameter log yang dicari. Pada akhirnya hasil korelasi tersebut dapat diterapkan di volume seismik sehingga didapatkan persebaran log yang dicari.

Dalam penelitian ini digunakan metode neural network yang mengorelasikan antara data seismik dengan data sumur. Prosesnya dengan menganalisis atribut terbaik yang berkorelasi dengan sumur, kemudian korelasi ini digunakan untuk mengetahui parameter sumur yang dicari. Parameter yang dicari pada penelitian ini yaitu porositas. Pada akhirnya setelah semua parameter yang dicari didapatkan, maka dapat dilakukan evaluasi terhadap zona target.

\section{METODOLOGI PENELITIAN}

\section{A. Rancangan Penelitian}

Penelitian ini dimulai dengan mendata seluruh data yang ada. Setelah itu setiap jenis data yang didapatkan diproses masing-masing. Ekstraksi wavelet dilakukan pada data seismik dan dari data well log dilakukan analisis log guna menentukan zona target berdasarkan kedalaman. Setelah itu dilakukan pengikatan antara data seismik dan data well guna mendapatkan data log dengan domain kedalaman, dengan bantuan data checkshot. Setelah itu dilakukan picking horizon 
pada lapisan sekitar target. Batas horizon yang didapat digunakan menjadi pembatas dalam melakukan inversi sehingga tidak memakan banyak waktu dalam prosesnya. Inversi impedansi akustik dilakukan dengan metode berbasis model. Setelah itu dilakukan prediksi porositas dengan menggunakan seismik multiatribut dan dioptimalisasi menggunakan metode PNN untuk mendapatkan hasil yang lebih sesuai dengan log porositas asli. Berdasarkan hasil yang didapatkan, lalu dilakukan analisis cross plot, inversi, multiatribut, slice, dan arbitrary line. Rancangan penelitian diilustrasikan pada Gambar 1.

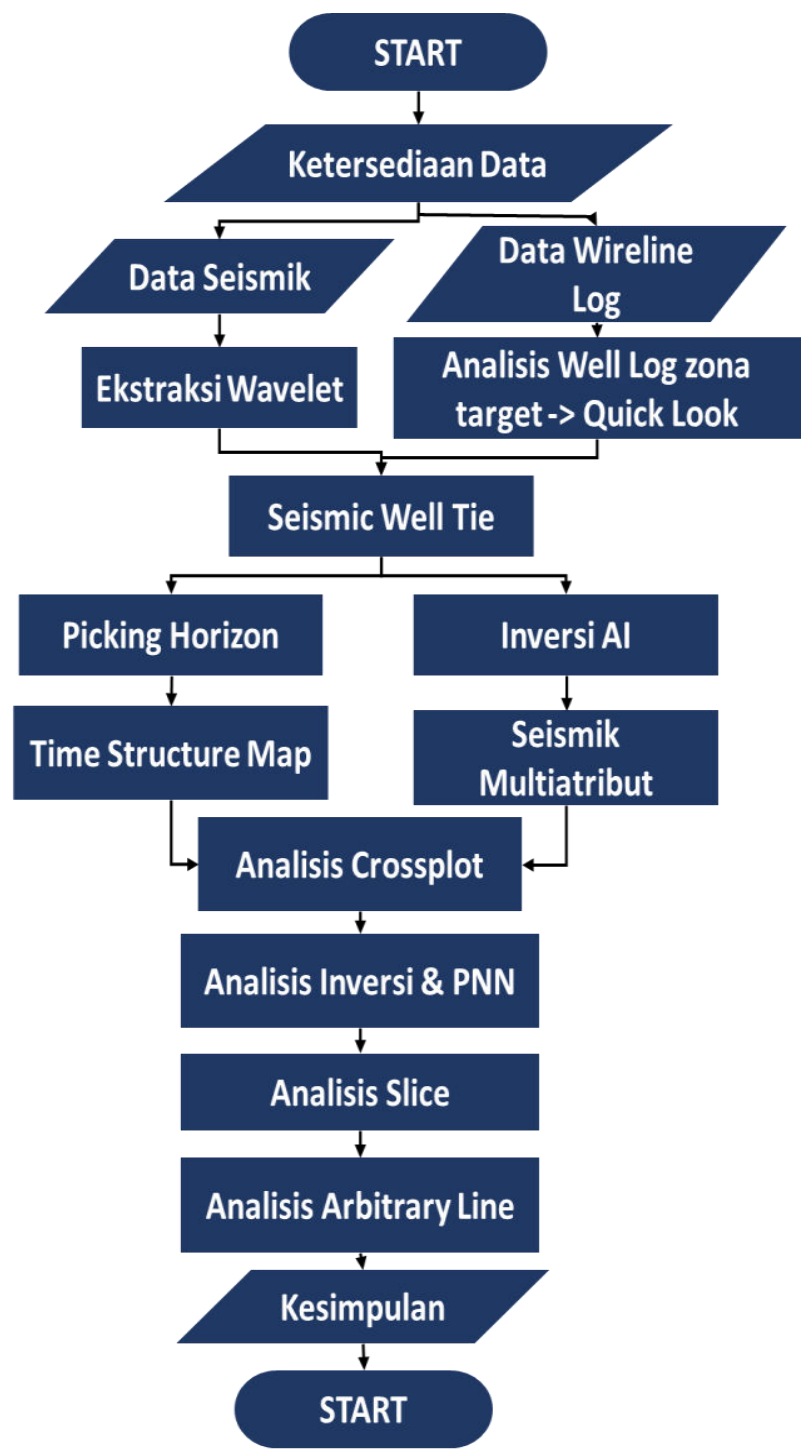

Gambar 1. Rancangan Penelitian.

\section{B. Neural Network}

Operasi non-linier dari neural network menghasilkan korelasi yang lebih baik dibandingkan dengan regresi linier multiatribut karena neural network bekerja dengan meniru cara otak manusia bekerja. Neural network dilakukan dengan batas atas marker zona target bagian atas (F1WC) dan sampai akhir log. Neural network menginterpolasi data dengan cukup baik, tetapi log yang mempunyai spike atau nilai yang cukup tinggi atau rendah hanya diambil trennya saja.

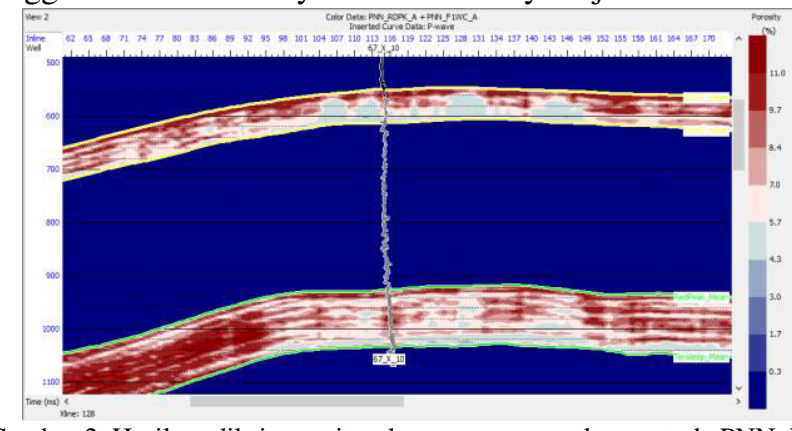

Gambar 2. Hasil prediksi porositas dengan menggunakan metode PNN. Nilai porositas pada penampang mempunyai rentang $4.3-11 \%$.

\section{HASIL DAN PEMBAHASAN}

\section{A. Analisis Terintegrasi Inversi AI dan PNN}

Setelah dilakukan analisis terhadap hasil inversi impedansi akustik berbasis model dan seismik multiatribut probabilistic neural network, maka akan dilakukan analisis terintegrasi guna mendapatkan karakter reservoar dari zona target. Pada analisis ini akan dikorelasikan antara persebaran nilai porositas dan impedansi akustik pada peta horizon dan penampang arbitrary line.

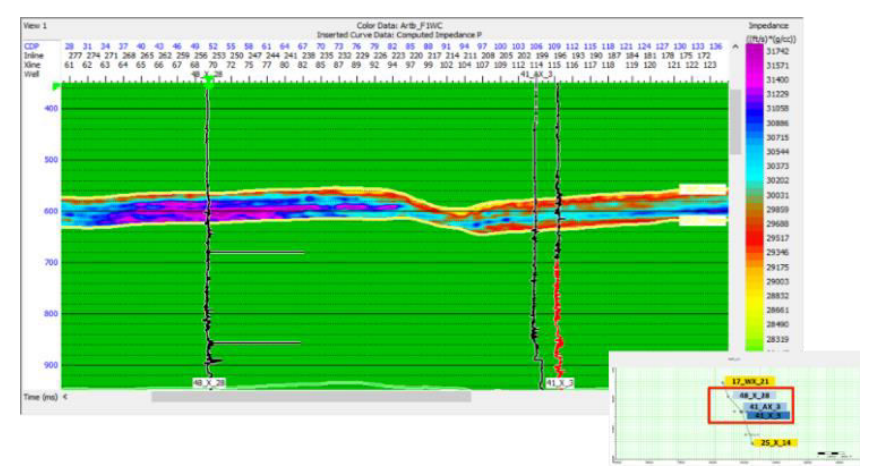

Gambar 3. Arbitrary line pada beberapa sumur berarah NW-SE di zona F1WC.

Berdasarkan Gambar 3, 4, dan 5 diketahui bahwa persebaran porositas dan impedansi akustik cenderung seragam dengan rentang nilai impedansi 27000-34000 $(\mathrm{ft} / \mathrm{s})(\mathrm{gr} / \mathrm{cc})$ dan porositas $8-11 \%$ pada peta porositas. Dari log GR didapatkan bahwa zona ini merupakan shaly sand dengan nilai GR>50 API. Berdasarkan data slice $+10 \mathrm{~ms}$, properti log yang bagus ditunjukkan pada well 17_WX_21, 48_X_28, dan 67_X_10 yang berada di area Utara dan Selatan dengan kisaran impedansi $30000(\mathrm{ft} / \mathrm{s})(\mathrm{gr} / \mathrm{cc})$, berwarna biru muda pada peta. Zona yang mempunyai properti bagus yaitu zona yang mempunyai impedansi rendah pada zona target F1WC ini. Pada arbitrary line menunjukkan bahwa persebaran impedansi properti yang bagus dengan warna biru muda hingga merah mempunyai persebaran yang merata. Berdasarkan hal-hal tersebut dapat dijustifikasi bahwa zona ini prospektif berdasarkan karakter log yang cukup bagus, nilai porositas yang cukup, dan karakter log resistivitas menyerupai zona di bawahnya yaitu F2WC yang sudah terbukti 
mengandung hidrokarbon.

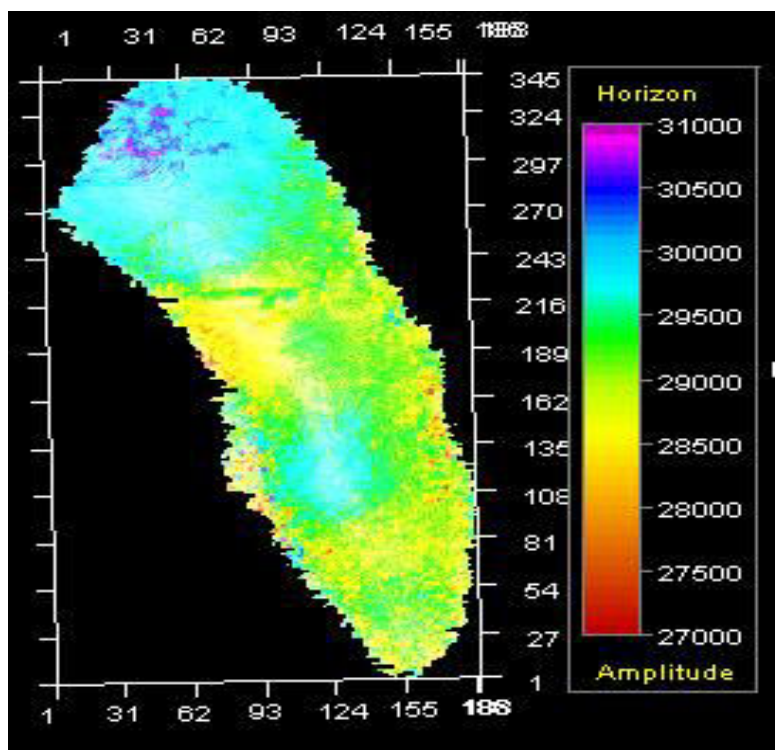

Gambar 4. Penampang timeslice pada horizon F1WC (+10ms).

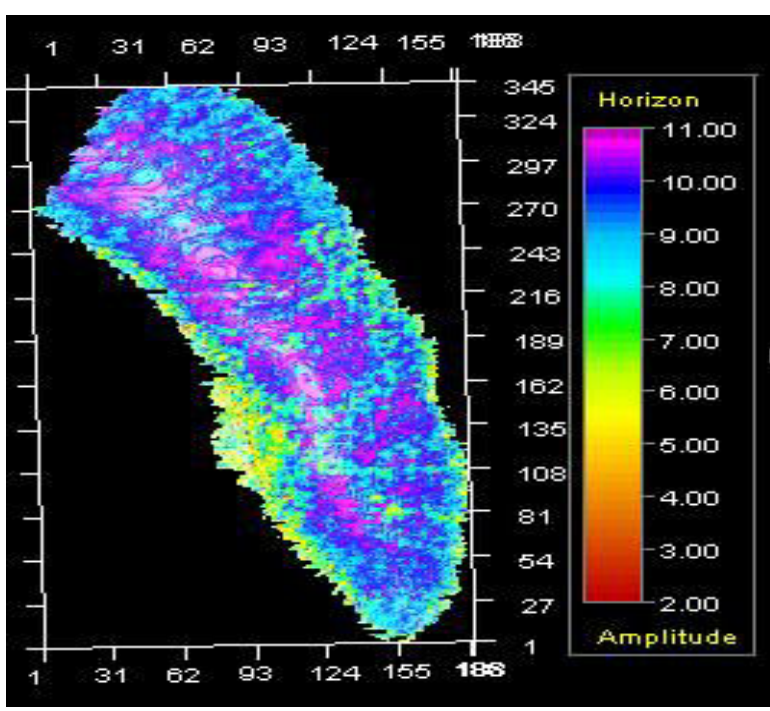

Gambar 5. Porosity map horizon F1WC +10ms.

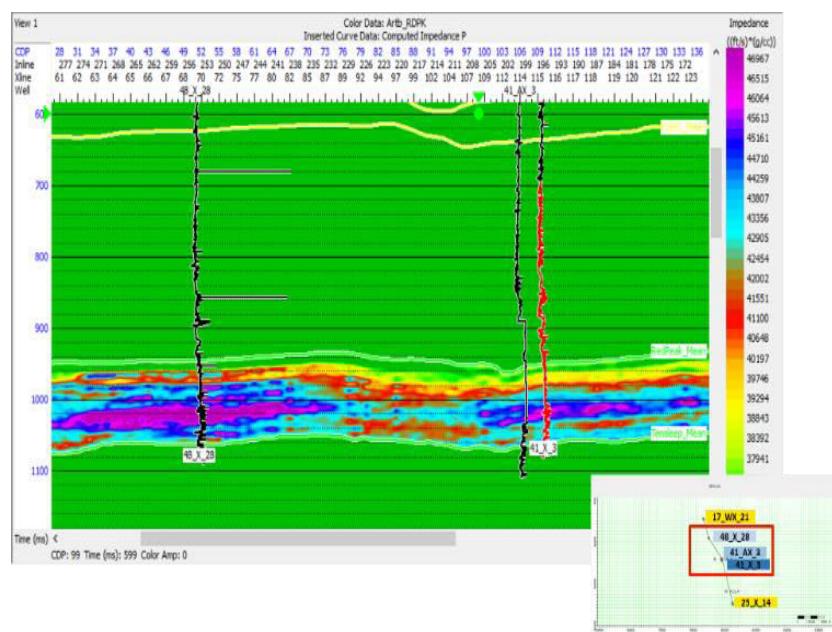

Gambar 6. Arbitrary line pada beberapa sumur berarah NW-SE di zona RDPK.

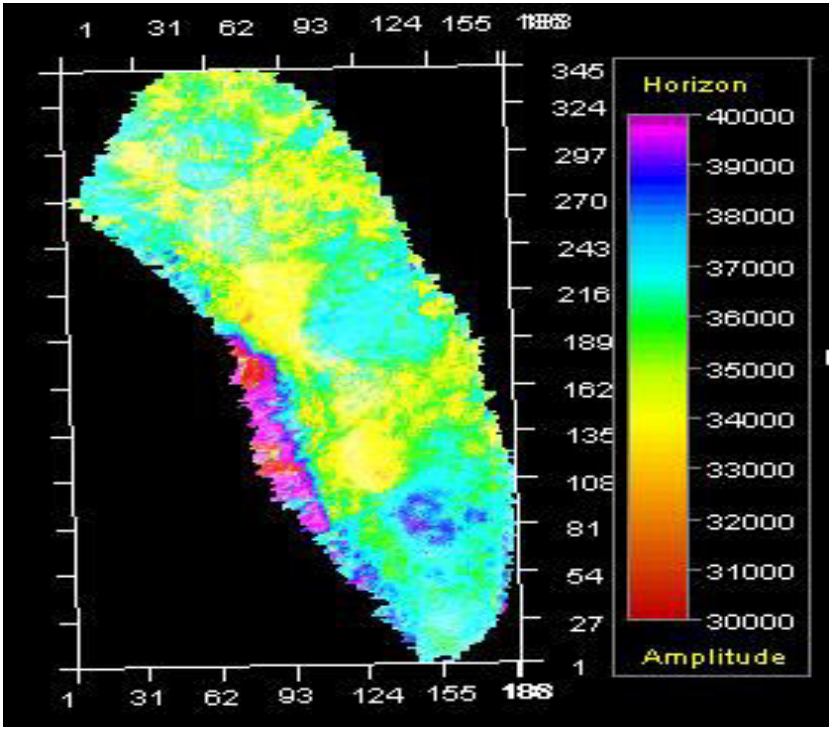

Gambar 7. Penampang timeslice pada horizon RDPK (+15ms).

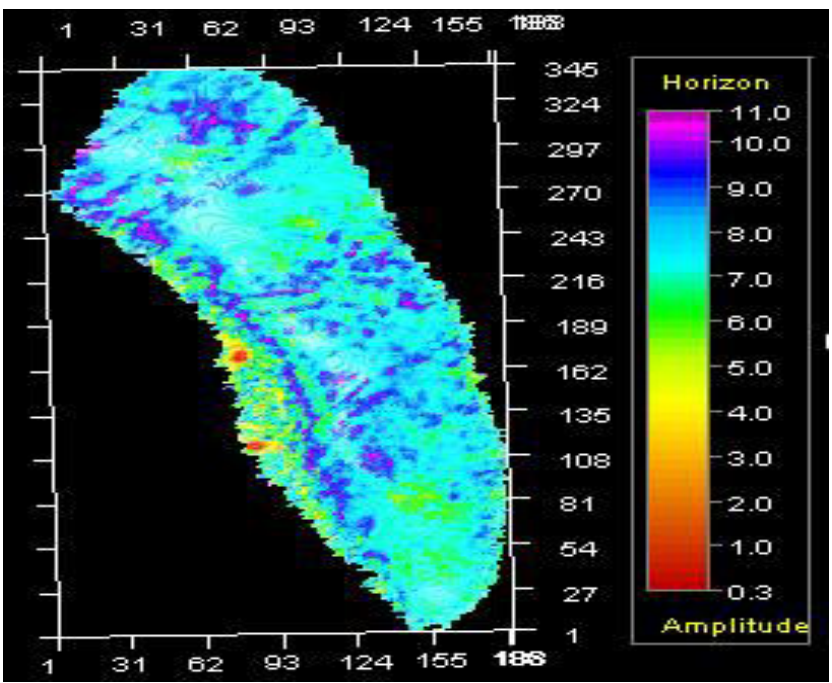

Gambar 8. Porosity map horizon RDPK $+15 \mathrm{~ms}$.

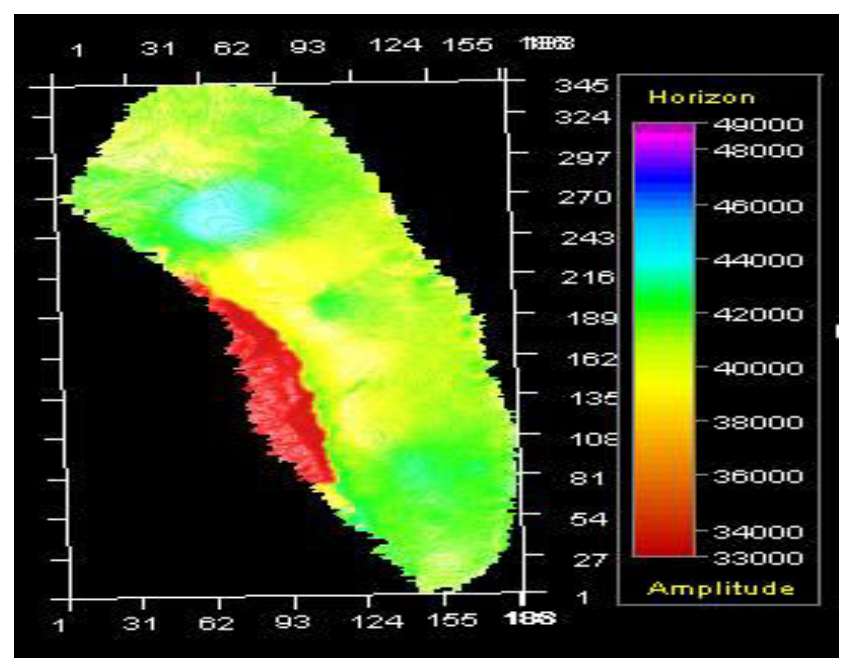


Gambar 9. Penampang timeslice pada horizon RDPK (+95ms).

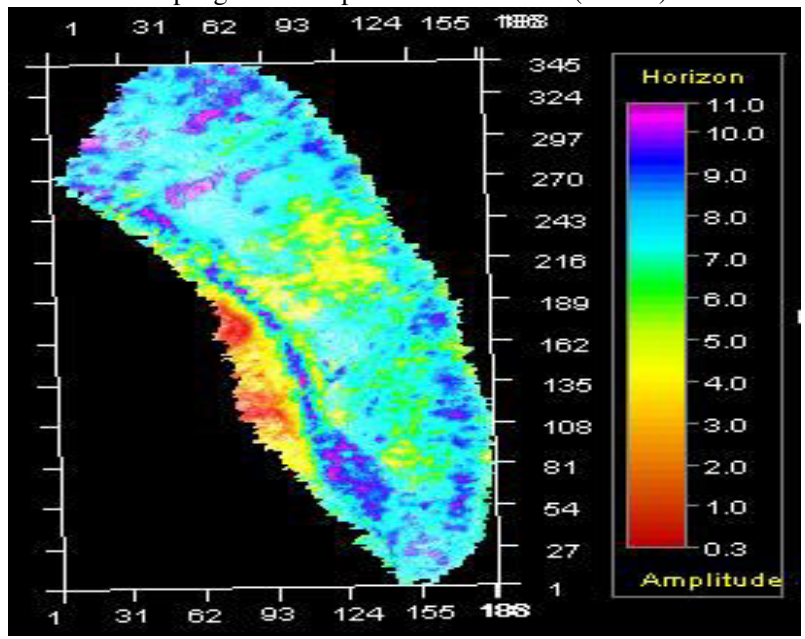

Gambar 10. Porosity map horizon RDPK +95ms.

Berdasarkan Gambar 6, 7, 8, 9, dan 10 diketahui bahwa persebaran impedansi akustik dan porositas cenderung seragam dengan rentang nilai impedansi $34000-49000$ $(\mathrm{ft} / \mathrm{s})(\mathrm{gr} / \mathrm{cc})$ dan porositas $5-10 \%$ pada peta. Berdasarkan log GR didapatkan bahwa zona ini merupakan campuran litologi clean sand hingga shaly sand dengan GR zona clean sand $<20$ API dan shaly sand pada zona ini memiliki nilai GR yang lebih rendah dibandingkan dengan yang di F1WC. Data slice pada zona ini diambil pada 2 lokasi, $+15 \mathrm{~ms}$ pada zona shaly sand dan +95 pada zona sand. Pada data slice $+15 \mathrm{~ms}$, properti yang bagus ditunjukkan dengan warna kuning hingga hijau muda dengan rentang impedansi $34000-37000(\mathrm{ft} / \mathrm{s})(\mathrm{gr} / \mathrm{cc})$ berdasarkan properti log dari well 67_X_10. Pada data slice +95ms, properti bagus merata kecuali pada lokasi dengan warna impedansi merah. Zona properti yang bagus ditunjukkan dengan impedansi yang tinggi. Pada peta slice porositas $+95 \mathrm{~ms}$, porositas yang bagus berada pada bagian Utara dan Selatan. Pada arbitrary line menunjukkan bahwa persebaran impedansi akustik properti yang bagus dengan warna biru muda hingga ungu merata antar well. Berdasarkan hal tersebut dapat dijustifikasi bahwa zona ini prospektif berdasarkan karakter log GR yang lebih clean, terdapat lokasi high resistivity di zona sand, nilai impedansi yang tinggi, dan nilai porositas yang cukup.

\section{KESIMPULAN}

Berdasarkan pengolahan data yang telah dilakukan diperoleh hasil guna mencapai tujuan dari penelitian ini, sehingga dapat disimpulkan bahwa :

1. Karakter reservoar zona F1WC yaitu impedansi akustik pada rentang 27000-34000 (ft/s)(gr/cc) dan porositas 8$11 \%$, dengan zona prospek merata.
2. Karakter reservoar zona RDPK mempunyai rentang nilai impedansi akustik 34000-49000 (ft/s)(gr/cc) dan porositas $5-10 \%$, dengan zona prospek berada di Utara dan Selatan.

3. Berdasarkan peta persebaran karakter reservoar, peta timeslice, dan karakter log diketahui bahwa zona target F1WC dan RDPK merupakan zona prospektif hidrokarbon.

\section{DAFTAR PUSTAKA}

[1] S. Sukmono, "Seismik Inversi untuk Karakterisasi Reservoar," Bandung, 2000.

[2] Artun, E. et al. 2005. Reservoir Characterization Using Intelligent Seismic Inversion. SPE 98012, Society of Petroleum Engineers

[3] Chamber, R. L. and Yarus, J. M.. 2008. Quantitative Use of Seismic Attribute for Reservoar Characterization Quantitative Geoscience, inc. Broken Arrow, Houston, Texas, USA.

[4] Cooper, S.P., Lorenz, J.C., dan Goodwin, L.B.. 2001. Lithologic and Structural Controls on Natural Fracture Characretistics Teapot Dome, Wyoming. Sandia National Laboratories Technical Report SAND 2001$1786,74 \mathrm{p}$.

[5] Fahmi, R.. 2016. Karakterisasi Reservoar Karbonat dengan Aplikasi SeismikAtribut dan Inversi Seismik Impedansi Akustik pada Lapangan "RF", JOB Pertamina Petrochina East Java. Skripsi, Institut Teknologi Sepuluh Nopember.

[6] Faisal. 2009. Prediksi Sebaran Porositas pada Lapisan Karbonat dengan Menggunakan Metode Inversi Berbasis Model pada Data Seismik 3D. Skripsi, Universitas Hasanuddin.

[7] Gadallah, R. M. dan Fisher, R.. 2009. Exploration Geophysics. Springer:Berlin.

[8] Gray, D. dan Andersen, E.. 2001. The Application of AVO and Inversion to the Estimation of Rock Properties. CSEG Recorder.

[9] Hampson, D. dan Russell, B. H.. 2005. Simultaneous Inversion of Prestack Seismik Data. Geohorizons.

[10]Harsono, Adi. 1997. Evaluasi Formasi dan Aplikasi Log. Jakarta : Schlumberger Oilfield Services.

[11] Irwan, F.. 2010. Aplikasi Inversi AI terhadap Karakterisasi Porositas Reservoar Lapangan IWR Cekungan Sumatera Utara. Tesis, Universitas Indonesia.

[12] Jordan, T.E., dan Allmendinger, R.W.. 1986. The Sierras Pampeanas of Argentina: A Modern Analogue of Rocky Mountain Foreland Deformation. American Journal of Science, v. 286, p. 737-764.

[13] Klusman, R.W.. 2005. Baseline Studies of Surface Gas Excange and SoilGas Composition in Preparation for CO2 Sequestration Research: Teapot Dome, Wyoming. American Association of Petroleum Geologists Bulletin, v. 89, no. 8, p. 981-1003.

[14]Rastegarnia, M. dan Kadkhodaie, A.. 2013. Estimation of Flow Zone Indicator Distribution by Using Seismic Data : A case study from a Central Iranian Oilfield. Iranian Journal of Oil \& Gas Science and Technology, Vol. 2 (2013), No.4, pp. 12.25.

[15]Roth, M., Emmanuel, J., Anderson, T.. 2005. Better Understanding Wyoming Tight Gas Reservoir Through Co-visualization and Analysist of 3D Seismic, VSP and Engineering Data-Teapot Dome, Powder River Basin. 3D Seismic Symposium, Rocky Mountain Association of Geologis/Denver Geological Society, p. 1-5.

[16] Saleeby, J.. 2003. Segmentation of the Laramide Slab-evidence from the southern Sierra Nevada Region. Geological Society of America Bulletin, v. 115 , no.6, p. 655-668.

[17] Singer, Julian. 2007. Well Loging for Earth Scientists. Netherland : Springer.

[18] Yuliandri, I., dkk.. 2014. Facies (Rock Type) Modeling Using Static Model Process from Porosity Distribution, Case from Baturaja Formation. AAPG International Conference and Excibition, Istanbul, Turkey. 